\title{
Examining Implementation of Risk Assessment in Case Management for Youth in the Justice System
}

\author{
Peterson-Badali, Michele., Skilling, Tracey., Haqanee, Zohrah. \\ Version Post-print/accepted manuscript \\ Citation Peterson-Badali, M., Skilling, T. \& Haqanee, Z. (2015). Examining \\ implementation of riskassessment in case management for youth in \\ the justice system. Criminal Justice and Behavior, 42(3), 304-320. \\ DOI http://dx.doi.org/10.1177/0093854814549595 \\ Publisher statement: Published by SAGE Publications
}


Running Head: IMPLEMENTATION OF RNR ASSESSMENT IN PRACTICE

Examining Implementation of Risk Assessment in Case Management

for Youth in the Justice System

Michele Peterson-Badali

University of Toronto

Tracey Skilling

Centre for Addiction and Mental Health \& University of Toronto

Zohrah Haqanee

University of Toronto

Michele Peterson-Badali, Department of Applied Psychology \& Human Development,

University of Toronto; Tracey Skilling, Department of Psychiatry, University of Toronto; Zohrah

Haqanee, Department of Applied Psychology \& Human Development, University of Toronto.

Author Note

This research was supported by Grant 410101516 from the Social Sciences and Humanities

Research Council of Canada to Michele Peterson-Badali. We would like to thank the following people for their contribution to the research: Nina Vitopoulos, Sarah McCormick, Sara Jaffer,

Kathy Underhill, Nadia Mazaheri, Greg Brown, Justices David Cole and Brian Weagant, Lisa

Capobianco, Nancy Peters, Natasha Dodd-Flake, Natasha Gribbon, and Rochelle Direnfeld.

Correspondence concerning this article should be addressed to Michele Peterson-Badali, Department of Applied Psychology \& Human Development, Ontario Institute for Studies in Education, University of Toronto, 252 Bloor Street West, $9^{\text {th }}$ Floor, Toronto, ON, Canada, M5S1V6. E-mail: m.petersonbadali@utoronto.ca 


\begin{abstract}
Research on implementation of a case management plan informed by valid risk assessment in justice services is important in contributing to evidence-based practice but has been neglected in youth justice. We examined the connections between risk assessment, treatment, and recidivism by focusing at the individual criminogenic need domain level. Controlling for static risk, dynamic criminogenic needs significantly predicted reoffense. Meeting individual needs in treatment was associated with decreased offending. However, there is 'slippage' in the system that reduces practitioners' ability to effectively address needs. Even in domains where interventions are available, many youth are not receiving services matched to their needs. Implications and limitations of findings are discussed.
\end{abstract}

Keywords: Risk-Need-Responsivity, youth, assessment, implementation, rehabilitation 


\section{Examining Implementation of Risk Assessment in Case Management for Youth in the Justice System}

\section{Introduction}

\section{'Risk-Needs' Assessment in the Youth Justice System}

For youth involved in the justice system, reliable and valid assessment is a critical step in establishing programming needs (e.g., types of interventions, levels of supervision). The science of risk assessment in forensic psychology practice has made substantial progress over the last several decades, evolving from judgments based on evaluators' clinical impressions and beliefs to structured tools that assess factors empirically established to predict reoffending. One of the most widely used models for assessment and case management of justice-involved youth is the Risk-Need-Responsivity (RNR) framework (Andrews \& Bonta, 2010a; Andrews, Bonta \& Hoge, 1990). Based on a substantial body of research conducted over the past several decades, the RNR framework outlines a systematic, evidence-based approach for evaluating an individual's risk of future offending and identifying the specific factors (criminogenic needs) that must be addressed to reduce risk, while paying heed to treatment modality (general responsivity) as well as individual characteristics such as cognitive ability, learning style, and motivation that may impact the effectiveness of interventions (specific responsivity). The RNR framework has itself expanded from a focus on risk prediction and offender classification to a more comprehensive approach that views assessment and classification as the basis for the development of a case management plan.

In North America and beyond, RNR-informed assessments are increasingly forming part of standard case management for youth under community supervision. In one commonly-used model, probation staff are trained in the RNR principles, to administer and score 'risk-needs' assessment tools, and to use assessment data to develop supervision/case management plans, 
including provision of, or referral for, rehabilitative interventions. In jurisdictions employing this model, probation-generated RNR assessments are typically conducted on all youth entering the probation system. Complementary to this approach are more in-depth and specialized assessments, typically carried out by forensic psychologists, psychiatrists, and other trained mental health professionals to assist courts with disposition planning, that may also include an explicit risk-need focus. There is a paucity of information available on why and how youth are referred for these court-ordered forensic assessments, which are conducted on a much smaller proportion of youth in the justice system (Jack \& Ogloff, 1997; Vieira, 2007). However - at least in some settings - they share in common with probation RNR-based assessments a focus on identifying youths' overall level of risk and specific criminogenic needs, as well as the generation of recommendations for service based on youths' risk level and needs (in addition to other - non-criminogenic - needs such as mental health and developmental concerns).

Until recently there has been a dearth of research examining how risk-needs assessments are used in practice, and whether their use is associated with relevant outcomes (e.g., reoffending). However, a growing body of literature on implementation of the RNR framework is addressing such issues, most commonly in the context of probation practice. Several studies have addressed the question of whether case management plans and activities are actually consistent with (or based on) the results of risk-needs assessments, with mixed results. For example, some studies reported a disconnect between the criminogenic needs identified in probationers' risk-needs assessments and the services listed on their case plans (Bonta, Scott, Rugge, Bourgon \& Yessine, 2008; Flores, Travis \& Latessa, 2004), the extent of which varied according to the particular need in question (Bonta et al, 2008). Bonta and colleagues (2008) also found that probation officers often did not address criminogenic needs with their clients in supervision sessions. In contrast, Luong and Wormith (2011) reported that youth probation 
officers' case management practices were consistent with RNR principles as evidenced by a correspondence between identified risk level and intensity of supervision (risk principle). They also noted correspondence between criminogenic need domain scores on a risk assessment instrument (the Level of Service Inventory-Saskatchewan Youth Edition; Andrews, Bonta \& Wormith, 2001) and: (1) identification by probation officers of those domains as need areas in youths' case management plans, and (2) interventions proposed in the case management plan (need principle). The greater degree of correspondence between case management and RNR principles found in this study compared to the Bonta et al. (2008) and Flores et al. (2004) studies may reflect the policy and standards of practice in place in the study's jurisdiction that clearly linked case management activities to RNR principles and assessment tools.

Probation officers' knowledge, skills, and beliefs about RNR principles and practices have been recognized as potentially important determinants of whether the framework is implemented as intended (Ballucci, 2012; Haas \& De Tardo-Bora, 2009; Luong \& Wormith, 2011; Vincent, Guy, Gershenson and McCabe, 2012). Because of this, researchers (e.g., Bonta et al., 2011; Vincent et al., 2012) have developed training programs explicitly designed to increase probation officers' adherence to the RNR principles in their case management. They reported that such training in RNR principles and specific RNR practices impacted probation officers' behavior (e.g., focus on criminogenic needs, such as antisocial attitudes, in supervision sessions; Bonta et al., 2011), and was associated with relevant client outcomes such as conviction on new offenses (Bonta et al., 2011) as well as out-of-home placements and levels of supervision (Vincent et al., 2012). Thus, there is evidence of a linkage between training in RNR principles and practices, and the behavior of case managers.

Finally, in addition to the wealth of literature supporting the general efficacy of the RNR framework for reducing reoffending (Andrews \& Bonta, 2010a,b; Andrews, et al., 1990) recent 
research indicates that case management practice targeted to probationers' individually-identified criminogenic needs (i.e., attention to the Need Principle at the individual level) is associated with reduced reoffending (Vieira, Skilling \& Peterson-Badali, 2009), at least for male (Vitopoulos, Peterson-Badali, \& Skilling, 2012) and high-risk (Luong \& Wormith, 2011) youth, which supports the ultimate goal of case management. However, while these studies have focused on the overall extent of service match across the dynamic criminogenic needs domains, it is important to examine implementation at the individual domain level. For example, criminogenic need domains vary in strength as predictors of recidivism; antisocial attitudes, peers, and personality comprise the three dynamic risk domains of the 'Big Four' predictors of reoffending (Andrews \& Bonta, 2010a; Skilling \& Sorge, in press) while other criminogenic needs (e.g., education/ employment, family circumstances, substance use) are more modestly related to recidivism. When devising and implementing a case management plan it is important to consider these distinctions, not only in terms of what the literature tells us about general risk prediction, but in relation to individual clients, whose needs across domains may vary from none/low to high or very high. In addition, practically-speaking, case managers focus at the individual domain level in their work and may need to prioritize treatment in one domain over another in their case planning (Haqanee, Peterson-Badali, \& Skilling, 2014). Indeed, there is some evidence that identified criminogenic needs vary in terms of the extent to which they are addressed in case management (Bonta et al., 2008; Luong \& Wormith, 2011; Vitopoulos et al., 2012).

The goal of the present study was to further examine the connections between risk assessment, treatment designation, and recidivism, with a focus on the individual criminogenic domain level. First, we wanted to ascertain the extent to which risk/need scores informed the treatment recommendations of youth forensic assessments. This first link - the correspondence between RNR assessment and recommendations - is critical to address, assuming that such 
recommendations drive case management activities, particularly referrals for intervention. We next examined the extent to which identified needs were actually addressed in case management (either directly by probation officers or through referrals for services). The third key question related to the link between service-to-needs matching and reoffending. Thus, for each of the criminogenic need domains, we examined whether recidivism was predicted by whether or not youths' identified needs were met ('matched') through services provided by, or arranged through, probation case managers.

\section{Method}

\section{Participants}

Data from 148 (129 male and 19 female) youth who completed a court-ordered forensic assessment at a mental health center in Toronto, Canada for assistance in making or reviewing a disposition between 2004 and 2009 were used for the present study. Cases consisted of consecutive admissions to the service for whom probation records could be obtained and who consented to the use of their data for research purposes; $86 \%$ of clients provided such consent. Participants ranged in age from $12-19^{1}$ at the time of assessment ( $M=16.1$ years, $S D=1.63$ years). As Table 1 shows, the sample was primarily White or Black. In terms of the most serious index offense, almost $60 \%$ of participants were charged with a violent but not sexual offense (e.g., robbery, assault, murder); approximately $20 \%$ were charged with either a non-violent offense (e.g., failure to comply with probation or court order, theft, drug-related, breaking and entering) or a sexual offense (i.e., aggravated sexual assault, sexual assault, invitation to touching). Excluding Conduct Disorder, just over half of the sample (55.5\%) was diagnosed with at least one psychiatric disorder at assessment. ${ }^{2}$ There were no gender differences in diagnosis except that a greater proportion of girls than boys were diagnosed with Mood and/or Anxiety disorders (see Table 1). 


\section{Procedure}

Data used in the present study were coded from participants' clinical files (which contained background information as well as the court ordered assessment reports mentioned above), probation case notes, and criminal records. Court-ordered assessments, completed just prior to youths' sentencing hearings, were conducted by a member of a multidisciplinary team in a child and adolescent mental health program specializing in forensic assessments; they included evaluations of risk-needs (see below), mental health, and cognitive and academic functioning, as well as recommendations to address identified needs. Team members were psychiatrists, psychologists, or social workers; all were trained in the administration and interpretation of the risk-needs assessment measure.

To extract data for the current study, participants' clinical charts were reviewed to gather information on demographics, offense history, charges leading to referral for assessment, scores on the risk-needs assessment measure (the Youth Level of Service/Case Management Inventory; YLS/CMI, Hoge \& Andrews, 2002), and assessing clinicians' recommendations contained in the resulting court report. The information gathered for the court-ordered assessments, and used by assessing clinicians to score the YLS/CMI, came from semi-structured clinical interviews with multiple informants, standardized questionnaires and psychological tests, and collateral sources of information obtained during their assessments. Participants' probation files were reviewed to ascertain what components of their sentence were completed, including services to address criminogenic needs. This information was used to determine whether the services received matched the recommendations made by the assessing clinicians in the seven YLS/CMI dynamic criminogenic needs domains.

\section{Measures}


Risk to offend and criminogenic needs. The YLS/CMI (Hoge \& Andrews, 2002, 2011) assesses 12 to 18 year-old youths' overall risk to reoffend, criminogenic needs, and responsivity factors. The first section consists of a 42-item checklist of youth risk and needs factors in eight categories: history of criminal conduct (which, though it is a significant predictor of recidivism, is not a treatment target) and seven criminogenic need domains (family circumstances and parenting, current school/ employment functioning, peer affiliations, alcohol and drug use, leisure and recreational activities, personality and behavior, and antisocial attitudes). Each item is coded as present or absent. Within each domain, items are summed and the domain score is assigned a categorical descriptor (low, medium, high). A total risk score is calculated by summing all items.

Studies indicate that the YLS/CMI has moderate to strong internal consistency for most subscales (Schmidt, Hoge \& Gomes, 2005; Vitopoulos et al., 2012). Correlations between YLS/CMI total scores and broad and narrow band scores on the Child Behavior Checklist (Schmidt et al., 2005) and the Youth Self Report (Skilling \& Sorge, in press) provide strong evidence of concurrent validity. Predictive validity is moderate to strong for male and female youth, with significant correlations between YLS/CMI total scores and number of subsequent offenses, as well as time elapsed prior to a new offense (Olver, Stockdale \& Wormith, 2009, 2014). In the current dataset, inter-rater reliabilities for the YLS/CMI total score among the primary clinicians, as measured by Pearson correlations, ranged from .80 to .98 (average r=.93) on a subsample of youth where the YLS/CMI rating was independently completed by two raters. Clinician recommendations and matching service to recommendations. As in previous studies (e.g., Vieira et al., 2009; Vitopoulos et al. 2012) the question of 'match' was addressed in terms of whether youths received services as recommended in their assessment reports. Clinician recommendations were coded according to a 3-point scale that reflected the explicitness of the recommendation in the youth's 
assessment report. For each domain, a score of 0 reflected no mention of the need in the report, a score of 1 was assigned when the need was mentioned in the body of the report (but not the recommendations section), and a score of 2 indicated that the need was flagged in the recommendation section of the report. Service-to-clinician recommendation matching was coded for each of the seven dynamic criminogenic need domains by comparing clinician recommendations to information regarding probation service provision, program assignment, and attendance recorded in youths' probation files. For each criminogenic need domain, where the clinician recommendation variable was coded either 1 or 2 (i.e., where a criminogenic need was identified as needing attention somewhere in the report) probation case notes were reviewed to determine whether the need was addressed, either directly by probation officers or through referrals for service. ${ }^{3}$

Both 'quality' and 'quantity' of services were considered when coding match. While it was not possible to ascertain detailed information about quality of services (e.g., treatment integrity) through case notes, information in the notes allowed judgments to be made about the extent to which services were evidence-based (e.g., use of recognized, manualized programs, cognitive-behavioral techniques) and delivered by appropriate services providers (e.g., trained professionals versus community volunteers). In terms of quantity, both the length of a program (in terms of number of hours of service that constitute the program) as well as the extent to which the youth attended the program (completed, attended majority of sessions, attended rarely or not at all) informed match coding. A 'match' was coded as absent (0) when an identified need was not mentioned in probation case notes, when a referral was made for programming but not followed through either because of a wait list or because the youth rarely attended sessions (a 'quantity' problem), when a youth received programming that was of low intensity when higher intensity service was recommended, or when service was not at least evidence-informed ('quality' problems). For example, if substance use was identified as a concern in the report (clinician recommendation code of either 1 or 2), a match was coded as absent, or 'no' (0), if a youth received nothing more than a few brief sessions with a volunteer to address substance use issues. A match was coded as present, or 'yes' (1), when probation records indicated that the youth completed, or attended most of the sessions of, a 
recognized (i.e., evidence-based) substance use program. Two raters independently reviewed the assessment recommendations and case notes for $20 \%$ of the files to code for match; reliability was excellent (Landis \& Koch, 1977), with Cohen's Kappas ranging from .89 to 1.0 across domains.

Recidivism. Recidivism was defined as whether or not a youth was convicted of one or more new offenses within an approximate three year follow-up period after the conviction which precipitated his or her entry into the sample; data were obtained from a national police criminal record database. Reoffenses were included only if they represented new charges (and not offenses for which youths were already in the system) that occurred after the assessments were complete and the youth was sentenced. In addition, in order to provide time for probation services to be implemented, reoffenses that occurred within three months of the date of assessment were not considered recidivism.

\section{Results}

\section{Preliminary Analyses}

Table 1 provides information on youths' demographic, offense, criminogenic need, and recidivism characteristics by gender. Youths' mean total YLS/CMI score was $19.30(\mathrm{SD}=9.59)$, which falls into the Moderate Risk range (Hoge \& Andrews, 2002). The overall recidivism rate was $59 \%$, with girls somewhat less likely than boys to reoffend. Mean time to reoffense was approximately 15 months for recidivists; 10 youths $(9 \%)$ reoffended within six months. Subsequent convictions were coded according to most serious offense; most were substantive (e.g., assault, property offenses) rather than administrative in nature.

An examination of the implementation of risk-needs assessment in practice is predicated on the assumption that the scores from a risk assessment tool do, in fact, successfully predict recidivism. Therefore, before addressing our primary research questions, we first examined whether youths' total YLS/CMI scores significantly predicted recidivism. The total YLS/CMI 
score correlated with recidivism at $.40(p<.001)$. A logistic regression analysis resulted in a significant model $\left(\chi^{2}(1)=28.97, \mathrm{p}<.0001\right)$; its sole predictor, the total YLS/CMI score, was also significant $\left(\right.$ Wald $\left.\chi^{2}=23.30, \mathrm{p}<.0001, \mathrm{OR}=1.11 ; 95 \% \mathrm{CI}=1.06-1.16\right)$. For each unit increase on the YLS/CMI, youth were $11 \%$ more likely to reoffend. A Receiver Operating Characteristic (ROC) analysis was also conducted to examine the ability of the model to correctly classify individuals. The area under the curve (AUC) statistic was significant $(0.75, p<.0001)$, indicating that the model classified the sample significantly better than by chance; at a $95 \%$ confidence interval, there was a $75 \%$ probability that a randomly selected recidivist would obtain a higher YLS/CMI score than a randomly selected non-recidivist (CI range $=.67-.83$ ). Additional information related to these analyses is available on request.

It is also important to ascertain the contribution of dynamic risk scores, beyond static risk, to the prediction of reoffending as, from a programming perspective, dynamic factors (criminogenic needs) are the necessary targets of service because these are the factors that are amenable to change. Turning to the domain level, bivariate correlations indicated that criminogenic need scores were generally more highly related to one another than to recidivism (see Table 2) but all correlations with recidivism, with the exception of the family domain score, were significant. In order to examine the contribution of criminogenic needs beyond static risk, recidivism was regressed on static risk (criminal history) at step 1 and the seven criminogenic needs domains were added at step 2 of a hierarchical logistic regression analysis. The model was significant at both steps (Step 1 Model $\chi^{2}(1)=29.36, \mathrm{p}<.0001$; Step 2 Model $\left.\chi^{2}(8)=46.38, \mathrm{p}<.0001\right)$ and criminal history contributed significantly to the model at both steps (Wald $\chi^{2}=23.69, \mathrm{p}<.0001, \mathrm{OR}=1.72(95 \% \mathrm{CI}=1.38-2.14)$ at Step 1 and Wald $\chi^{2}=6.69, \mathrm{p}=.01$, $\mathrm{OR}=1.45(95 \% \mathrm{CI}=1.10-1.93$ at Step 2$)$. The addition of the dynamic risk domains at step 2 contributed significantly to the model $\left(\chi^{2}(7)=17.01, p<.05\right)$, with antisocial attitudes acting as 
a significant dynamic need predictor $\left(\right.$ Wald $\chi^{2}=5.93, \mathrm{p}<.05, \mathrm{OR}=1.56,95 \% \mathrm{CI}=1.10-2.22$ ). Taken together, the findings indicate that criminogenic needs do contribute to the prediction of re-offense, which provides support for efforts to target these needs in case management.

\section{To what extent do risk/need scores inform the treatment recommendations of youth}

\section{forensic assessments?}

For each criminogenic need domain, Column 1 of Table 3 displays the percentage of cases for which a given need area was identified as requiring attention, either in the body of the report or in the recommendations section. These figures range from 50\% (attitude and substance use domains) to $93 \%$ (education/employment), indicating that clinicians frequently identified needs across domains as areas of concern. In order to examine whether clinician identification of needs as requiring intervention was related to youths' risk/need scores in those domains, oneway ANOVAs were run for each of the seven dynamic criminogenic need domains to compare the YLS/CMI domain scores across the three categories of clinician recommendation: no mention of need in report; mention of need in body of report only; need discussed in recommendations section of report. If clinicians' recommendations follow RNR principles, a YLS/CMI score in a given domain should be higher when that domain is discussed in the report recommendations (and even when mentioned in the body of the report) than when the need is not mentioned in the report. Indeed, for the Family $(F(2,145)=13.32, \mathrm{p}<.0001)$, Education/ Employment $(\mathrm{F}(2,145)=5.77, \mathrm{p}<.01)$, Personality $(\mathrm{F}(2,145)=38.57, \mathrm{p}<.0001)$, Attitude $(\mathrm{F}(2,145)=37.82, \mathrm{p}<.0001)$, and Peer $(\mathrm{F}(2,145)=20.50, \mathrm{p}<.0001)$ domains, mean YLS/CMI scores were significantly higher for youth who had these needs mentioned in their reports (whether specifically in the recommendations section or not) than when they were not mentioned. In the Leisure domain $(\mathrm{F}(2,145)=11.35, \mathrm{p}<.0001)$, the mean YLS/CMI score was higher when the need was flagged in the recommendations section than when it was mentioned 
in the body of the report or not mentioned at all; there was no difference in YLS scores between the latter two groups.

For the Substance Abuse domain, the relationship between the YLS domain score and the clinicians' decision to highlight the domain and make recommendations was even more clearly related. Specifically, the highest YLS/CMI mean score was associated with the group in which substance abuse was discussed in the report recommendations $(M=3.0)$ followed by the group in which this need was mentioned in the body of the report (though not in the recommendations section; $M=2.2$ ), which was in turn higher than the mean score for the group in which substance use was not mentioned at all $(\mathrm{M}=0.4)(\mathrm{F}(2,145)=95.43, \mathrm{p}<.0001)$; all pairwise differences were significant.

Overall, the correspondence between YLS/CMI domain scores and identification of needs in the report supports the interpretation that YLS/CMI scores did inform clinicians' decisions regarding recommendations.

\section{To What Extent are Identified Needs Addressed in Case Management?}

In contrast to the substantial proportions of cases in which needs were flagged in youths' reports across the seven domains, those needs were matched with appropriate intervention at much lower rates. As Column 2 of Table 3 shows, of those youth who had needs identified by clinicians in their assessment reports, the proportion of matched needs ranged from $15 \%$ (in the attitude domain) to $42 \%$ (in the education/employment domain), with needs being met in a fifth to a third of cases in the other criminogenic need domains. Collapsing across the criminogenic need domains, on average clinicians identified five of the seven domains as requiring attention for each youth but only 1.41 identified needs, on average, were actually addressed during probation and $40 \%$ of participants had none of their identified needs matched. The overall proportion of service-to-recommendation matching was 30.7\% (SD=33.3\%). 


\section{Relationship between Needs-matching and Recidivism}

Table 3 shows the percentage of youth, by criminogenic need domain, who reoffended despite receiving treatment targeted to an identified need (Column 3) as well as those who reoffended when there was not a match (Column 4). In each of the domains the effect was in the expected direction, with a failure to meet recommendations with intervention ('no-match') associated with greater likelihood of reoffending than when a service match was achieved; chi square analyses were significant for five of six domains analyzed (family, education/ employment, personality, leisure, and peer $)^{4}$. However, when recidivism was predicted by treatment match controlling for static risk (YLS criminal history scores), the match variable was significant in only the personality and leisure domains, with the family match $(p=.06)$ and education/employment match ( $\mathrm{p}=.07)$ predictors approaching significance (see Table 4$)$.

\section{Discussion}

It is instructive to consider implementation of the RNR framework - and the risk/needs assessments that operationalize it - in terms of a sequence of steps or conditions that need to be fulfilled in order for the principles to be achieved in practice. In the present study we endeavoured to examine several of these steps in order to illuminate the process and identify where 'slippage' is occurring (i.e., gaps that may hinder efforts to reduce reoffending and promote rehabilitation in justice-involved youth).

\section{Predicting Reoffending with the YLS/CMI}

The first step in this process was to confirm that the tool used to measure risk and needs (the YLS/CMI) was in fact predictive of youths' reoffending. Consistent with previous research (Olver et al., 2009; 2014), the YLS/CMI did significantly predict recidivism in our sample of youth, a result that constitutes a necessary starting point for use of the instrument as a case management tool. In addition, as a group, the dynamic risk factors predicted recidivism over and 
above criminal history, which speaks to the relevance of attending to dynamic criminogenic needs during youths' probation terms in an effort to promote desistance and is consistent with several recent studies examining the incremental contribution of dynamic risk factors to reoffense (McGrath \& Thompson, 2012; Vincent, Chapman \& Cook, 2011; Vincent, Perrault, Guy \& Gershenson, 2012). It is interesting to note that the only criminogenic need domain to emerge as a significant individual predictor of reoffending was antisocial attitudes. The importance of this particular criminogenic need is also highlighted in recent research reporting the positive impact of addressing antisocial attitudes with clients directly in probation case management (Bonta et al., 2011). That most of the dynamic criminogenic needs were not significant predictors on their own may, at least in part, be due to the fact that there is a fair bit of shared variance across the various domains. However, this does not detract from the interpretation of dynamic need domains as relevant targets of intervention, especially in light of the effects of matching them on recidivism, discussed below.

\section{Correspondence between Risk/Need Scores and Clinician Recommendations}

With this as a starting point, we turned our attention to the individual criminogenic need domains and asked the question: 'to what extent is there correspondence between YLS/CMI domain scores and reference to those domains in the body or recommendations section of youths' assessment reports?' This is a crucial question because practitioners' use of a RNRbased tool (in this case the YLS/CMI) to identify areas of need and generate recommendations to be taken up in case management is an essential first step in the effective implementation of the RNR framework. In the present study, for each of the seven dynamic criminogenic need domains, YLS/CMI scores were significantly higher for youth who had the need identified in their reports than for youth whose assessments did not mention the need. Due to the retrospective and cross-sectional nature of the study design, it is not possible to conclude that 
clinicians' inclusion of criminogenic needs in their assessment reports (i.e., decisions regarding whether to identify particular needs, inclusion of needs in recommendations) was driven by their clients' YLS/CMI domain scores. However, the fact that there was correspondence between youths' scores and clinicians' reporting is encouraging. It is interesting that for five of the seven domains (Family, Education/Employment, Personality, Attitude, and Peers) YLS/CMI scores did not differ significantly depending on whether the need was reflected explicitly in the recommendations section of the report versus mentioned in the report body (but not in the recommendations). Assuming that clinicians are attending to youths' YLS/CMI scores in writing their reports, it may be that a score (or corresponding risk category) determines whether a clinician addresses that domain as a need in a youth's report but that decisions about what to include in recommendations are reflective of varied considerations and not simply the level of risk presented in a given domain. Anecdotally, for instance, clinicians have noted that identified criminogenic needs (e.g., antisocial attitudes) are sometimes not reflected in report recommendations due to lack of services in the community designed to address those needs (and this point is also related to the discussion below on matching).

In this regard, it is interesting that the substance use domain was the one criminogenic need area in which there were significant mean differences between all recommendation categories (i.e., no mention of need in report vs. need mentioned in body vs. need explicitly contained in recommendations). This may reflect the specificity or concreteness of substance use in terms of its assessment (e.g., that permits clinicians to distinguish between 'typical' versus 'concerning' levels of substance use) but also the availability of targeted, evidence-based intervention programs for youth in the community, which gives clinicians something specific to recommend in order to address youths' needs in this area. Unfortunately, the greater specificity highlighted in the assessment reports in this domain did not translate into an increase in service 
matching, suggesting that additional considerations are at play in moving from recommendations to service delivery, as discussed next.

\section{$\underline{\text { Meeting Identified Needs with Probation Services }}$}

The next step along the implementation pathway is to ascertain whether the criminogenic needs identified in youths' assessments are actually addressed during probation. In the current study, criminogenic needs were mentioned in a minimum of $50 \%$ of youths' assessment reports (in the case of the substance use and antisocial attitudes domains), with some need areas mentioned almost universally (e.g., education and/or employment, in $93 \%$ of reports in the sample). However, these needs were 'matched' (i.e., identified needs addressed through case management - in terms of direct service provision by probation officers, or through referral to school or community programs and services) at much lower rates, ranging from a high of $42 \%$, in the case of education/employment, to a low of $15 \%$, in the case of antisocial attitudes; in four of the seven need domains, the match rate was less than $25 \%$. This constitutes a huge gap in the 'theory to practice' pathway, one that begs for both analysis and action.

Lack of available services in particular need areas is one significant explanation for this disconnect in the match between identified needs and youths' receipt of intervention. For example, despite the fact that the current study was conducted in a large, densely populated urban area that is relatively well-serviced compared to smaller and more remote communities, there are few services specifically targeted to youths' antisocial attitudes and antisocial peer affiliations. Indeed, lack of appropriate services was identified by youth probation officers as a significant barrier to addressing their clients' criminogenic needs (Haqanee, et al., 2014). The importance of directly targeting criminogenic needs (and in particular, antisocial attitudes) in case management, paired with evidence that probation officers were not doing so (Bonta et al., 2008), prompted the development of a structured training program for probation officers (the 
Strategic Training Initiative in Community Supervision (STICS); Bonta et al., 2011), which has been shown to be effective in reducing recidivism with adult offenders on probation. The implementation of such training on a more widespread basis might well help to address this match gap as probation officers target these criminogenic needs directly with their clients.

Additional barriers to addressing youths' criminogenic needs in community supervision have been identified by probation officers and may account for the poor rate of needs-to-service match. In the Haqanee et al. (2014) study of youth probation officers' experiences of meeting their clients' criminogenic needs, probation officers reported factors at the individual, systemic, and organizational levels that impeded their ability to help clients make change. For example, the interrelated factors of youths' motivation to engage in supervision and participate in treatment services in the context of often longstanding, entrenched, and complex family and community system-level problems (e.g., parental mental illness or antisociality, unsafe, high crime neighborhoods, disengagement from school) were discussed by probation officers as significant barriers to addressing criminogenic needs. Respondents also reported the need to prioritize noncriminogenic needs (e.g., mental health, housing) over criminogenic ones in order to provide sufficient stability so that clients could engage in education/employment and treatment services, and to focus on particular criminogenic needs at the expense of others because their clients were only willing and/or able to work on a limited number of issues at one time.

The importance of identifying and addressing the issues that are impeding efforts to effectively meet youths' needs through case management is underscored by our findings that appropriately matching needs with services is associated with decreased recidivism. In each of the dynamic criminogenic need domains (with the exception of antisocial attitudes, where the small number of matched cases precluded analysis), chi square analyses indicated that participants with identified needs that were matched with services reoffended at significantly 
lower rates than youth whose needs were not matched. Even when controlling for youths' criminal history, the effect of service-to-need matching significantly predicted recidivism in the personality and leisure domains and approached significance in the family and education/employment domains. The small number of cases in which needs were matched across the various need domains - and particularly in the substance use $(\mathrm{N}=16)$ and attitude $(\mathrm{N}=11)$ domains - means that these analyses are conservative measures of the effect of service matching. This limitation should be addressed in future research examining the effect of matching at the individual domain level with a larger sample of 'matched' cases.

\section{$\underline{\text { Study Limitations and Future Research Directions }}$}

Our study methods and results suggest several directions for future research. Forensic assessments are conducted on a small proportion of justice-involved youth who tend - as in this study - to present with a higher rate of serious charges than is typical of Canadian justiceinvolved youth as a whole (Thomas, 2008). However, it should be noted that participants' assessed risk fell in the moderate range overall, which is comparable to other samples of nonreferred custodial youth (Hoge \& Andrews, 2011). In addition, despite the fact that participants were referred for mental health assessments, rates and types of serious mental health concerns do not appear to be significantly different from non-referred custodial youth in terms of their rates of mental health diagnoses, which have been shown to be high across numerous studies (e.g., Wasserman, McReynolds, Schwalbe, Keating, \& Jones, 2010; Shufelt \& Cocozza, 2006; Skowyra \& Cocozza, 2007; Stahlberg, Anckarsater, \& Nilsson, 2010; Teplin, Abram, McClelland, Dulcan, \& Mericle, 2002; Wasserman, McReynolds, Lucas, Fisher, \& Santos, 2002; Wasserman, McReynolds, Schwalbe, Keating, \& Jones, 2010).). In terms of external validity, it will be important to examine implementation issues in RNR-based practice - including the question of service-to-need match - using the risk-needs assessments conducted by probation officers 
themselves. While these assessments will almost certainly be much briefer than comprehensive, clinically-generated forensic assessments, they reflect typical practice in many probation settings across North America and internationally and, as such, it will be possible to gather data on a broader and more representative sample of youth in the justice system.

Another methodological limitation (although this is consistent with much of the research in this area) is that information on case management activities - including direct service provision by probation officers and referral to community resources, school programming, and intervention services - used to code whether there was a service-to-needs match - was obtained from probation case notes. This documentation is required for all contacts with clients and collaterals and contains important information about case management activities, clients' attendance and engagement in supervision, treatment, and school and/or work. However, the detail in this documentation varies across cases and our findings are limited to the extent that this source of documentation diverges from a complete accounting of all variables relevant to a youth's criminogenic needs.

In terms of future directions for research, the current study consisted of a retrospective review of assessment information and probation case management. Prospectively following youth from assessment through probation assignment and beyond would allow for an examination of change in criminogenic needs over time and the ability to link changes to particular events (e.g., intervention services completed, school attendance, etc.), which in turn strengthens our ability to interpret relationships and make causal inferences. Related to this, examining change in dynamic criminogenic needs over the course of youths' probation term and assessing whether service-to-need matching predicts such changes, as well as whether changes in risk scores and/or the subsequent scores themselves, are associated with recidivism, is an important direction for future research. Several studies (e.g., Brooks Holliday, Heilbrun \& Fretz, 
2012) have documented change in need scores in various criminogenic domains associated with RNR-based case management (including targeted programming) with incarcerated adult offenders, although it remains to be seen whether changes in individual need domains are associated with reoffending.

In addition, as discussed above, the extent of the gap between identified needs and successful intervention to address those needs was substantial and presents a significant challenge to the successful implementation of the RNR framework in practice. Exploring barriers to implementation directly with front line workers is one useful approach to address the need to unpack this problem further (e.g., Haqanee et al., 2014). Research that explores and specifies which variables (e.g., at the individual, systemic - i.e., family, school, and community - and organizational levels) predict service-to-needs matching in the various criminogenic need domains also has potential to elucidate the barriers to effective implementation of the RNR framework and provide direction for policy and practice in this regard.

In summary, the results suggest there is much to be optimistic about in the youth justice service delivery including the findings that clinicians appear to be using a structured, empirically supported, assessment tool to understand risk to reoffend and to guide their treatment planning related to criminogenic needs; that these dynamic criminogenic needs are related to future difficulties, highlighting the opportunity to intervene; and importantly that intervening in these domains, decreases a young person's risk for reoffense. The results also highlight many opportunities for improving practice and preventing 'slippage' at each point in the service delivery pathway, in particular that many of the needs of many youth are going unmet. Given the positive impacts seen, with less than ideal practices in place, it is encouraging to imagine the potential for change if the gaps can be addressed. 
Table 1: Demographic, Diagnostic, Criminal charge, YLS/CMI, and Recidivism Characteristics by Gender

\begin{tabular}{lrrrr} 
Variable & Males & Females & Total & $\mathrm{t}$-test $/ \chi^{2}$ \\
\hline Age (years) & & & & \\
& 16.11 & 16.16 & 16.11 & $\mathrm{t}=-0.12, \mathrm{p}=.90$ \\
\% Ethnicity (n in brackets) & & & & \\
Black & & & & \\
White & $47.8(32)$ & $75.0(6)$ & $50.7(38)$ & $\chi^{2}(3)=3.78, \mathrm{p}=.29$ \\
Asian & $19.4(13)$ & $25.0(2)$ & $20.0(15)$ & \\
Other & $7.5(5)$ & $0.0(0)$ & $6.7(5)$ & \\
Total & $25.4(17)$ & $0.0(0)$ & $22.7(17)$ & \\
& $100(67)$ & $100(8)$ & $100(75)$ & \\
\% DSM Diagnosis (n in brackets) & & & & \\
ADHD & & & & \\
LD & $36.0(45)$ & $27.8(5)$ & $35.0(50)$ & $\chi^{2}(1)=0.18,=0.67^{1}$ \\
Mood \&/or Anxiety & $8.0(10)$ & $0.0(0)$ & $7.0(10)$ & $\chi^{2}(1)=0.56,=0.45^{1}$ \\
Substance & $11.2(14)$ & $33.3(6)$ & $14.0(20)$ & $\chi^{2}(1)=4.70, \mathrm{p}=.03^{1}$ \\
Other & $16.0(20)$ & $16.7(3)$ & $16.1(23)$ & $\chi^{2}(1)=0.00, \mathrm{p}=1.0^{1}$ \\
& $8.8(11)$ & $11.1(2)$ & $9.1(13)$ & $\chi^{2}(1)=0.00, \mathrm{p}=.1 .0^{1}$
\end{tabular}

\section{YLS/CMI Mean Scores}

Total Risk

Criminal History

Family

Education/Employment

Peer

Substance Abuse

Leisure

Personality

Attitudes

$\%$ Index Offense ( $\mathrm{n}$ in brackets)

Non-violent

Violent (non-sexual)

Sexual

$\begin{array}{rrrr}19.14 & 20.42 & 19.30 & \mathrm{t}=-0.55, \mathrm{p}=.59 \\ 1.84 & 2.42 & 1.91 & \mathrm{t}=-1.26, \mathrm{p}=.21 \\ 3.16 & 3.84 & 3.25 & \mathrm{t}=-1.56, \mathrm{p}=.12 \\ 4.08 & 3.89 & 4.05 & \mathrm{t}=0.36, \mathrm{p}=.72 \\ 2.12 & 2.21 & 2.13 & \mathrm{t}=-0.31, \mathrm{p}=.76 \\ 1.55 & 2.00 & 1.61 & \mathrm{t}=-1.10, \mathrm{p}=.27 \\ 1.52 & 1.74 & 1.55 & \mathrm{t}=-0.91, \mathrm{p}=.36 \\ 3.12 & 3.11 & 3.12 & \mathrm{t}=0.04, \mathrm{p}=.97 \\ 1.75 & 1.21 & 1.68 & \mathrm{t}=1.35, \mathrm{p}=.18\end{array}$

Recidivism-Yes ( $\mathrm{n}$ in brackets)

$19.4(24)$

$21.1(4) \quad 19.6(28)$

$58.1(72) \quad 68.4(13) \quad 59.4(85)$

$22.6(28) \quad 10.5(2) \quad 21.0(30)$

Mean Days to Recidivism

for youth who reoffended $(n=87)$

$62.0(80)$

$36.8(7) \quad 58.8(87)$

$$
\chi^{2}(2)=1.46, p=.48
$$

$\%$ Reoffense Type ( $\mathrm{n}$ in brackets)

474.5

406.6

469.0

$\chi^{2}(1)=3.35, \underline{p}=.07^{1}$

$$
\mathrm{t}=-0.91 \mathrm{p}=.39
$$

\footnotetext{
${ }^{1}$ Corrected for continuity.
} 
Assault

Property

Robbery

Weapons

Administrative

Drug

Other

Missing
$25.3(22)$

$18.4(16)$

16.1 (14)

$10.3(9)$

$6.9(6)$

4.8 ( 4)

14.9 (13)

3.4 (3) 
Table 2. Correlations Between Recidivism (Yes/No) and YLS/CMI Total and Domain Scores

\begin{tabular}{|c|c|c|c|c|c|c|c|c|c|}
\hline $\begin{array}{l}\text { YLS } \\
\text { Domain }\end{array}$ & Recidivism & $\begin{array}{c}\text { Criminal } \\
\text { History }\end{array}$ & Family & Education & Peers & $\begin{array}{c}\text { Substance } \\
\text { Abuse }\end{array}$ & $\begin{array}{c}\text { Leisure } \\
\text { Time }\end{array}$ & Personality & Attitudes \\
\hline Recidivism & -- & & & & & & & & \\
\hline $\begin{array}{r}\text { Criminal } \\
\text { History }\end{array}$ & .43 & -- & & & & & & & \\
\hline Family & .16 & .32 & -- & & & & & & \\
\hline Education & .27 & .39 & .39 & -- & & & & & \\
\hline Peers & .38 & .49 & .39 & .50 & -- & & & & \\
\hline $\begin{array}{l}\text { Substance } \\
\text { Abuse }\end{array}$ & .27 & .58 & .38 & .41 & .49 & -- & & & \\
\hline $\begin{array}{l}\text { Leisure } \\
\text { Time }\end{array}$ & .39 & .50 & .35 & .45 & .54 & .45 & -- & & \\
\hline Personality & .25 & .35 & .46 & .61 & .35 & .33 & .36 & -- & \\
\hline Attitudes & .39 & .43 & .45 & .54 & .46 & .42 & .41 & .60 & -- \\
\hline Total Score & .43 & .71 & .66 & .77 & .70 & .70 & .66 & .75 & .76 \\
\hline
\end{tabular}

Note: All correlations except Family and Recidivism are significant at $\underline{\mathrm{p}}<.01$ or less, two-tailed. 
Table 3. Clinician Identification of Criminogenic Needs, Service Matching to Needs, and Relationship to Recidivism by Need Domain.

\begin{tabular}{|l|l|l|l|l|l|l|}
\hline Domain & $\begin{array}{l}\text { Need mentioned in report body } \\
\text { or recommendations }\end{array}$ & $\begin{array}{l}\text { Need } \\
\text { Matched }\end{array}$ & $\begin{array}{l}\text { Need Match but } \\
\text { Youth Reoffended }\end{array}$ & $\begin{array}{l}\text { No } \\
\text { Match }\end{array}$ & $\begin{array}{l}\text { No Match and } \\
\text { Youth Reoffended }\end{array}$ & $\begin{array}{l}\chi^{2} \text { for Match by } \\
\text { Reoffense }\end{array}$ \\
\hline Family & $82.4(122)$ & $32.8(40)$ & $40.0(16)$ & $67.2(82)$ & $72.0(59)$ & $10.28^{* * *}$ \\
\hline $\begin{array}{l}\text { Education/ } \\
\text { Employment }\end{array}$ & $93.2(137)$ & $41.6(57)$ & $45.6(26)$ & $58.4(80)$ & $71.2(57)$ & $8.12^{* *}$ \\
\hline Substance Use & $50.0(74)$ & $21.6(16)$ & $62.5(10)$ & $78.4(58)$ & $67.2(39)$ & 0.00 \\
\hline Personality & $77.0(114)$ & $30.7(35)$ & $42.9(15)$ & $69.3(79)$ & $82.3(65)$ & $16.17^{* * *}$ \\
\hline Attitude & $50.0(73)$ & $15.1(11)$ & $54.5(6)$ & $84.9(62)$ & $79.0(49)$ & -2 \\
\hline Leisure & $70.9(105)$ & $24.8(26)$ & $34.6(9)$ & $75.2(79)$ & $70.9(56)$ & $9.43^{* *}$ \\
\hline Peer & $76.4(113)$ & $19.5(22)$ & $45.5(10)$ & $80.5(91)$ & $72.5(66)$ & $4.73^{*}$ \\
\hline
\end{tabular}

$* \mathrm{p}<.05 ; * * \mathrm{p}<.01 * * * \mathrm{p}<=.001$

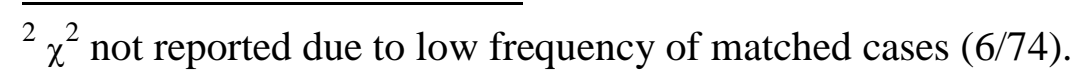


Table 4. Logistic Regressions - Recidivism Predicted by YLS/CMI Criminal History Score and Treatment Match for each Risk/Need Domain $^{3}$

\begin{tabular}{|c|c|c|c|c|c|c|c|c|c|c|}
\hline Domain & $\begin{array}{l}\beta \text { YLS } \\
\text { Criminal } \\
\text { History }\end{array}$ & Wald's $\chi^{2}$ & $\begin{array}{l}\text { Odds Ratio } \\
\text { (Exp B) }\end{array}$ & $\begin{array}{l}\text { CI (9 } \\
\text { Uppe }\end{array}$ & $\begin{array}{l}\text { \%) } \\
\text { Lower }\end{array}$ & $\begin{array}{l}\beta \text { Treatment } \\
\text { Match }\end{array}$ & $\begin{array}{l}\text { Wald's } \\
\chi^{2}\end{array}$ & $\begin{array}{l}\text { Odds } \\
\text { Ratio (Exp } \\
\text { B) }\end{array}$ & $\begin{array}{l}\text { CI (9 } \\
\text { Uppe }\end{array}$ & $\begin{array}{l}\%) \\
\text { Lower }\end{array}$ \\
\hline $\begin{array}{l}\text { Family } \\
(\mathrm{N}=122)\end{array}$ & .47 & $13.08 * * *$ & 1.59 & 1.24 & 2.05 & .86 & 3.69 & 2.35 & .98 & 5.63 \\
\hline $\begin{array}{l}\text { Education/ } \\
\text { Employment } \\
(\mathrm{N}=137)\end{array}$ & .55 & $19.90 * * *$ & 1.74 & 1.36 & 2.21 & 0.74 & 3.40 & 2.09 & .96 & 4.57 \\
\hline $\begin{array}{l}\text { Substance } \\
\text { Use }(N=74)\end{array}$ & .45 & $8.76^{* *}$ & 1.57 & 1.17 & 2.12 & .31 & 0.25 & 1.37 & .40 & 4.72 \\
\hline $\begin{array}{l}\text { Personality } \\
(\mathrm{N}=114)\end{array}$ & .36 & $7.28 * *$ & 1.44 & 1.10 & 1.87 & 1.65 & $12.38 * * *$ & 5.21 & 2.08 & 13.07 \\
\hline $\begin{array}{l}\text { Leisure } \\
(\mathrm{N}=105)\end{array}$ & .52 & $13.02 * * *$ & 1.68 & 1.27 & 2.22 & 1.04 & $3.94 *$ & 2.82 & 1.01 & 7.84 \\
\hline $\begin{array}{l}\text { Peer } \\
(\mathrm{N}=113)\end{array}$ & .45 & $11.96 * * *$ & 1.56 & 1.21 & 1.99 & .69 & 1.67 & 1.99 & .70 & 5.67 \\
\hline
\end{tabular}

$* \mathrm{p}<.05 ; * * \mathrm{p}<.01 * * * \mathrm{p}<.001$

\footnotetext{
${ }^{3}$ Sample size was insufficient to analyze the Attitude domain $(\mathrm{N}=11)$
} 


\section{References}

Andrews, D. A., \& Bonta, J. (2010a). The psychology of Criminal Conduct (5th Edition). New Providence, NJ: Matthew Bender \& Company.

Andrews, D. A., \& Bonta, J. (2010b). Rehabilitating criminal justice policy and practice. Psychology, Public Policy, and Law, 16, 39-55. doi:10.1037/a0018362

Andrews, D. A., Bonta, J., \& Hoge, R. D. (1990). Classification for effective rehabilitation: Rediscovering psychology. Criminal Justice and Behavior, 17, 19-52. doi:

\section{$10.1177 / 0093854890017001004$}

Andrews, D. A., Bonta, J., \& Wormith, J. S. (2001). Level of service inventory- Saskatchewan youth edition. Toronto, Ontario, Canada: Multi-Health Systems.

Ballucci, D. (2012). Subverting and negotiating risk Assessment: A case study of the LSI in a Canadian youth custody facility. Canadian Journal of Criminology \& Criminal Justice, 54, 203-228. doi:10.3138/cjccj.2010.E.27

Bonta, J., Bourgon, G., Rugge, T., Scott, T., Yessine, A., Gutierrez, L., \& Li, J. (2011). An experimental demonstration of training probation officers in evidence-based community supervision. Criminal Justice and Behavior, 38, 1127-1148. doi: $10.1177 / 0093854811420678$

Bonta, J., Rugge, T., Scott, T., Bourgon, G., \& Yessine, A. K. (2008). Exploring the black box of community supervision. Journal of Offender Rehabilitation, 47, 248-270. doi: $10.1080 / 10509670802134085$

Brooks Holliday, S., Heilbrun, K., \& Fretz, R. (2012). Examining improvement in criminogenic needs: The risk reduction potential of a structured re-entry program. Behavioral Sciences and the Law, 30, 431-447. doi: 10.1002/bsl.2016 
Flores, A. W., Travis, L. F., \& Latessa, E.J. (2004). Case classification for juvenile corrections: An assessment of the Youth Level of Service/Case Management Inventory (YLS/CMI). Cincinnati: Center for Criminal Justice Research, University of Cincinnati. Retrieved from https://www.ncjrs.gov/pdffiles1/nij/grants/204005.pdf

Haas, S. M., \& DeTardo-Bora, K. A. (2009). Inmate reentry and the utility of the LSI-R in case planning. Corrections Compendium, 11-16, 49-52.

Haqanee, Z., Peterson-Badali, M., \& Skilling, T.A. (2014). Making 'What Works' work: Examining probation officers' experiences addressing the criminogenic needs of juvenile offenders. Manuscript under review.

Hoge, R. D., \& Andrews, D. A. (2011). Youth Level of Service/Case Management Inventory 2.0. Toronto, ON: Multi-Health Systems Inc.

Hoge, R. D., \& Andrews, D. A. (2002). Youth Level of Service/Case Management Inventory: YLS/CMI Interview Guide. Toronto, ON: Multi-Health Systems Inc.

Jack, L. A., \& Ogloff, J. R. P. (1997). Factors affecting the referral of young offenders for medical and psychological assessment under the Young Offenders Act. Canadian Journal of Criminology, 39, 247-273.

Landis, J. R., \& Koch, G.G. (1977). The measurement of observer agreement for categorical data. Biometrics, 33, 159-174.

Luong, D., \& Wormith, J. (2011). Applying Risk/Need assessment to probation practice and its impact on the recidivism of young offenders. Criminal Justice and Behavior, 38, 1177-1199. doi: 10.1177/0093854811421596 
McGrath, A., \& Thompson, A. P. (2012). The relative predictive validity of the static and dynamic domain scores in Risk-Need assessment of juvenile offenders. Criminal Justice and Behavior, 39, 250-263. doi: 10.1177/0093854811431917

Olver, M. E., Stockdale, K. C., \& Wormith, J. S. (2014). Thirty years of research on the level of service scales: A meta-analytic examination of predictive accuracy and sources of variability. Psychological Assessment, 26, 156-176. doi: 10.1037/a0035080.

Olver, M. E., Stockdale, K. C., \& Wormith, J. S. (2009). Risk assessment with young offenders: A meta-analysis of three assessment measures. Criminal Justice and Behavior, 36, 329353.

Schmidt, F., Hoge, R. D., \& Gomes, L. (2005). Reliability and validity analyses of the Youth Level of Service/Case Management Inventory. Criminal Justice and Behavior, 32, 329-3. doi: $10.1177 / 0093854804274373$

Shufelt, J.S., \& Cocozza, J.C. (2006). Youth with mental health disorders in the juvenile justice system: Results from a multi-state, multi-system prevalence study. Delmar, NY: National Center for Mental Health and Juvenile Justice.

Skilling, T.A., \& Sorge, G. (in press). Measuring antisocial values and attitudes in justiceinvolved male youth: Evaluating the usefulness of the Pride in Delinquency and Criminal Sentiments Scale. Criminal Justice and Behavior.

Skowyra, K. R., \& Cocozza, J. J. (2007). Blueprint for change: A comprehensive model for the identification and treatment of youth with mental health needs in contact with the juvenile justice system. Delmar, NY: The National Center for Mental Health and Juvenile Justice. 
Stahlberg, O., Anckarsatar, H., \& Nilsson, T. (2010). Mental health problems in youths committed to juvenile institutions: Prevalences and treatment needs. European Child \& Adolescent Psychiatry, 19, 893 - 903.

Teplin, L. A., Abram, K. M., McClelland, G. M., Dulcan, M. K., \& Mericle, A. A. (2002). Psychiatric disorders in youth in juvenile detention. Archives of General Psychiatry, 59, 1133-1143. doi: 10.1001/archpsyc.59.12.1133.

Thomas, J. (2008). Youth Court Statistics, 2006/2007. Juristat. Catalogue no. 85002, Vol. 28, no. 4. Ottawa, Statistics Canada. Canadian Centre for Justice Statistics. Retrieved from: http://www.statcan.gc.ca/pub/85-002-x/2008004/article/10568-eng.htm

Vieira, T. (2007). Matching court-ordered services with youths' clinically-identified treatment needs: Predicting treatment success with young offenders. (Doctoral Dissertation). Retrieved from ProQuest UMI Dissertations Publishing. (Accession Number NR39513).

Vieira, T., Skilling, T., \& Peterson-Badali, M. (2009). Matching court-ordered services with youths' treatment needs: Predicting treatment success with young offenders. Criminal Justice and Behavior, 36, 385-401. doi: 10.1177/0093854808331249

Vincent, G. M., Chapman, J., \& Cook, N. E. (2011). Risk-needs assessment in juvenile justice: Predictive validity of the SAVRY, racial differences and the contribution of needs factors. Criminal Justice and Behavior, 38, 42-62. doi: 10.1177/0093854810386000

Vincent, G.M., Guy, L.S., Gershenson, B.G., \& McCabe, P. (2012). Does risk assessment make a difference? Results of Implementing the SAVRY in juvenile probation. Behavioral Sciences and the Law, 30, 384-405. doi: 10.1002/bsl.2014 
Vincent, G.M., Perrault, R.T., Guy, L.S., \& Gershenson, B.G. (2012). Developmental issues in risk assessment: Implications for juvenile justice. Victims and Offenders, 7, 364-384. doi: $10.1080 / 15564886.2012 .713900$

Vitopoulos, N., Peterson-Badali, M., \& Skilling, T. (2012). The efficacy of the Risk-NeedResponsivity framework in guiding intervention for justice system-involved female youth. Criminal Justice \& Behavior, 39, 1025-1041. doi: 10.1177/0093854812442895

Wasserman G. A., McReynolds L. S., Lucas C. P., Fisher P., \& Santos, L. (2002). The Voice DISC-IV with incarcerated male youths: Prevalence of disorder. Journal of the American Academy of Child and Adolescent Psychiatry, 41, 314-321.

Wasserman G., A., McReynolds, L. S., Schwalbe, C. S., Keating, J. M., \& Jones, S. A. (2010).

Psychiatric disorder, comorbidity, and Suicidal behavior in juvenile justice youth. Criminal Justice and Behavior, 37, 1361-1376. doi: 10.1177/0093854810382751 


\section{End Notes}

${ }^{1}$ Although the YLS-CMI was designed for use with youth aged 12 to 18 years, the tool was also used on the five 19 year old youth in our sample, who were processed in the youth system because their offense was committed before their $18^{\text {th }}$ birthday. Further, the youth were detained after their offense resulting in no further opportunity for many of the developmental changes reflected on the adult version of the YLS. For example, the youth continued to go to school, have the support of their parents, and to not be involved in romantic relationships involving significant commitments. Therefore use of the youth version of the tool was deemed more appropriate from a criminogenic need and responsivity perspective.

${ }^{2}$ Frequency of Conduct Disorder (CD) diagnoses is not reported. In the forensic service in which the assessments were conducted not all clinicians consistently made CD diagnoses even when criteria were met; these clinicians did not perceive the CD label as useful in describing justiceinvolved youth since so many would, by definition, meet criteria. Thus, frequency data on CD diagnosis did not accurately reflect the actual number of youth who met diagnostic criteria.

${ }^{3}$ We coded matches for YLS domains that were identified as needs by clinicians in the assessment reports; we did not code matches where a particular criminogenic need had not been identified and the need had correspondingly not been addressed during a youth's probation term. Although there is theoretical support for this latter 'absence' type of match, practically-speaking, including these matches tends to overwhelm (and obscure) the data where needs have been identified; therefore we did not code the 'absence' matches.

${ }^{4}$ Due to the small number of matched cases, it was not possible to analyze the treatment match for the attitude domain in chi square or regression analyses. 
Author Biographical Sketches

Michele Peterson-Badali is a professor in the Department of Applied Psychology and Human Development at the University of Toronto, Canada. Her research interests include intervention with youth in the justice system, with a focus on implementation of risk-need-responsivity principles in practice; the intersection of youth justice and mental health; and Aboriginal youth justice.

Tracey A. Skilling is a psychologist and clinician scientist at the Centre for Addiction and Mental Health and an assistant professor in the Department of Psychiatry at the University of Toronto, Canada. Her research interests include antisocial behavior, mental health issues, and substance use in adolescents; the construct of psychopathy; and risk assessment issues in both male and female young offenders. Her current projects include studies of the developmental precursors of psychopathic traits in adolescents and evaluating risk assessment practices with adolescent male and female offenders using the risk-need-responsivity framework.

Zohrah Haqanee is a Ph.D student in the Department of Applied Psychology and Human Development at the University of Toronto. Her research interests include examining educational achievement for youth on probation and the role it plays in desistance from crime; implementation of the need and responsivity principles in practice for youth in the justice system; and stigma related to mental illness. 